\title{
Long-term adaptation of the human lung tumor cell line A549 to increasing concentrations of hydrogen peroxide
}

\author{
Abdullah Onul • Kim M. Elseth • Humberto De Vitto • William A. Paradise • \\ Benjamin J. Vesper • Gabor Tarjan • G. Kenneth Haines III • Franklin D. Rumjanek • \\ James A. Radosevich
}

Received: 30 September 2011 / Accepted: 7 November 2011

(C) International Society of Oncology and BioMarkers (ISOBM) 2012

\begin{abstract}
Previously, we demonstrated that A549, a human lung cancer cell line, could be adapted to the free radical nitric oxide $\left(\mathrm{NO}^{\bullet}\right)$. $\mathrm{NO}^{\bullet}$ is known to be over expressed in human tumors. The original cell line, A549 (parent), and the newly adapted A549-HNO (which has a more aggressive phenotype) serve as a useful model system to study the biology of $\mathrm{NO}^{\bullet}$. To see if tumor cells can similarly be adapted to any free radical with the same outcome, herein we successfully adapted A549 cells to high levels of
\end{abstract}

A. Onul · K. M. Elseth · H. De Vitto - W. A. Paradise •

B. J. Vesper J. A. Radosevich

Center for Molecular Biology of Oral Diseases,

College of Dentistry, University of Illinois at Chicago,

801 S. Paulina St.,

Chicago, IL 60612, USA

A. Onul $\cdot$ K. M. Elseth $\cdot$ H. De Vitto $\cdot$ W. A. Paradise •

B. J. Vesper $\cdot$ J. A. Radosevich

Jesse Brown VAMC,

Chicago, IL 60612, USA

H. De Vitto $・$ F. D. Rumjanek

Universidade Federal do Rio de Janeiro, IbqM,

Rio de Janeiro, Brazil

J. A. Radosevich $(\bowtie)$

Oral Medicine and Diagnostic Sciences, College of Dentistry,

University of Illinois at Chicago,

Chicago, IL 60612, USA

e-mail: jrados@uic.edu

G. Tarjan

Department of Pathology, John H. Stroger, Jr.,

Hospital of Cook County,

Chicago, IL 60612, USA

G. K. Haines III

Department of Pathology, Yale University School of Medicine, New Haven, CT 06510, USA hydrogen peroxide (HHP). A549-HHP, the resulting cell line, was more resistant and grew better then the parent cell line, and showed the following characteristics: (1) resistance to hydrogen peroxide, (2) resistance to $\mathrm{NO}^{\bullet}$, (3) growth with and without hydrogen peroxide, and (4) resistance to doxorubicin. Gene chip analysis was used to determine the global gene expression changes between A549-parent and A549-HHP and revealed significant changes in the expression of over 1,700 genes. This gene profile was markedly different from that obtained from the A549-HNO cell line. The mitochondrial DNA content of the A549-HHP line determined by quantitative PCR favored a change for a more anaerobic metabolic profile. Our findings suggest that any free radical can induce resistance to other free radicals; this is especially important given that radiation therapy and many chemotherapeutic agents exert their effect via free radicals. Utilizing this model system to better understand the role of free radicals in tumor biology will help to develop new therapeutic approaches to treat lung cancer.

Keywords Adenocarcinoma Lung cancer $\cdot$ Reactive oxygen species (ROS) $\cdot$ Hydrogen peroxide $\cdot$ Nitric oxide . Cross-resistance $\cdot$ Cellular adaptation

\section{Introduction}

Lung cancer is a leading cause of death worldwide [1]. In the USA, the American Cancer Society's most recent statistics (2010) estimated that 222,520 people were diagnosed with lung cancer, and there were 157,300 deaths from this disease [2]. It has been shown that reactive oxygen species (ROS) and reactive nitrogen species (RNS) play a key role in human cancer development [3-8]. 
ROS is a collective term that includes both oxygen radicals and certain non-radicals, such as hydrogen peroxide $\left(\mathrm{H}_{2} \mathrm{O}_{2}\right)$, which can spontaneously break down into oxygen radicals. RNS is also a collective term that includes nitric oxide radical $\left(\mathrm{NO}^{\bullet}\right)$ and nitrogen dioxide radical $\left(\mathrm{NO}_{2}{ }^{\bullet}\right)$, as well as other nitrogen-based non-radicals which can break down into nitrogen radicals [9]. Major sources of ROS/RNS include the endogenous aerobic metabolism within cells and/or cells exposed to ROS/RNS from various exogenous sources. Almost all normal cell types within the body have been shown to produce both ROS and RNS. These are produced at very low levels and are associated with normal cell functions. Additionally, ROS/RNS play important roles in many biological processes, including serving as intracellular signaling molecules and growth stimulators $[10,11]$. The production of ROS/RNS at different levels can be either beneficial or harmful to the cells. Low concentrations of ROS/RNS have been shown to be beneficial for cells by altering mitogenic signals, activating transcription factors, and inducing apoptosis $[12,13]$. On the other hand, elevated levels of ROS/RNS have been shown to be harmful for cells and is associated with initiation of cancer [10]. Excessive amounts of ROS/RNS can cause structural alterations in DNA, affect cytoplasmic and nuclear signal transduction pathways $[14,15]$, and modulate the activity of the proteins and genes that respond to stress; these changes induced by excessive ROS/RNS levels act to regulate the genes that are related to cell proliferation, differentiation, and apoptosis $[4$, 14-17].

In the human body, free radicals are formed by multiple chemical reactions. Oxidative phosphorylation, a mitochondrial process which generates ATP, is coupled with a reaction in which $\mathrm{O}_{2}$ is reduced to $\mathrm{H}_{2} \mathrm{O}$. It is not clear what species is directly responsible for each of the biological activities where ROS have been implicated; however, there is a significant amount of experimental data that supports the idea that exposing normal cells to increasing concentrations of $\mathrm{H}_{2} \mathrm{O}_{2}$ results in carcinogenesis. It is known that $\mathrm{H}_{2} \mathrm{O}_{2}$ is associated with DNA damage, mutations, and genetic instability [18-23]; $\mathrm{H}_{2} \mathrm{O}_{2}$-induced DNA damage has been shown to be mediated by ${ }^{\bullet} \mathrm{OH}$ generated from $\mathrm{H}_{2} \mathrm{O}_{2}$ (the Fenton reaction) [18, 20, 22]. Several studies have also demonstrated that $\mathrm{H}_{2} \mathrm{O}_{2}$ can induce cell proliferation [14, 24, 25], apoptosis resistance [26, 27], increased angiogenesis [28, 29], invasion, and metastasis [24, 30, 31].

In a previous study, we adapted A549 (parent) cells to a nitrogen-based free radical, DETA-NONOate, which resulted in a new cell line A549-HNO [32]. In that study, we demonstrated that, in the presence of $\mathrm{H}_{2} \mathrm{O}_{2}, \mathrm{~A} 549-\mathrm{HNO}$ cells tolerated a higher concentration of $\mathrm{H}_{2} \mathrm{O}_{2}$ than the A549-parent cells. These initial results suggested that the A549-parent cell line could possibly be adapted to $\mathrm{H}_{2} \mathrm{O}_{2}$. However, it remained unclear as to whether cells adapted to
$\mathrm{H}_{2} \mathrm{O}_{2}$ would also be resistant to increased levels of $\mathrm{NO}^{\bullet}$ exposure. Herein we set out to adapt the A549-parent cells to an oxygen-based free radical rather than a nitrogen-based free radical.

\section{Materials and methodology}

Cell culture and cell lines

In this study, we used A549, a human lung adenocarcinoma cell line, which was purchased from American Type Culture Collection (Manassas, VA, USA). A549 was grown in RPMI-1640 media which contained $2 \mathrm{mM}$ L-glutamine, $2.5 \mu \mathrm{g} / \mathrm{mL}$ amphotericin B solution, $100 \mu \mathrm{g} / \mathrm{mL}$ streptomycin, $100 \mathrm{U} / \mathrm{mL}$ penicillin, and $10 \%$ fetal calf serum inactivated at $56^{\circ} \mathrm{C}$ for $30 \mathrm{~min}$. RPMI- 1640 media and all components were purchased from Invitrogen (Carlsbad, CA, USA). The cell line was grown in a humidified incubator at $37^{\circ} \mathrm{C}$ and $5 \% \mathrm{CO}_{2}$. All other reagents were obtained from Sigma-Aldrich (St. Louis, MO, USA) unless otherwise stated.

In previous work, we adapted A549 cells to DETANONOate to produce the cell line A549-HNO [32]; A549HNO cells were utilized in the studies reported herein and were maintained as previously described [32].

\section{Verification of adaptation end-point}

A549-parent and A549-HNO cells were seeded into 96well plates and grown for $24 \mathrm{~h}$ to $\sim 70 \%$ confluency in normal media (without hydrogen peroxide). Cells were then exposed to media containing various concentrations (0$9.6 \mathrm{mM})$ of hydrogen peroxide. The plates were then incubated for $24 \mathrm{~h}$, at which time a 3-(4,5-dimethylthiazol2-yl)-2,5-diphenyltetrazolium bromide (MTT; Sigma, St. Louis, MO, USA) cell proliferation/viability assay was performed. The media was removed, and $100 \mu \mathrm{L}$ of $2 \mathrm{mg} / \mathrm{mL}$ of MTT in phosphate buffer saline (PBS) was added to each of the wells. Plates were incubated at $37^{\circ} \mathrm{C}$ for $5 \mathrm{~h}$, and the MTT was removed. The remaining purple formazan crystals were dissolved in $100 \mu \mathrm{L}$ of dimethyl sulfoxide (DMSO), and a SpectraMax ${ }^{\circledR}$ Plus 384 spectrophotometer (Molecular Devices, Sunnyvale, CA, USA) was used to read the absorbance of each well at $540 \mathrm{~nm}$.

\section{Cell adaptation process}

In this study, A549 (parent cell line) was adapted over a 70-day period using a $30 \%$ hydrogen peroxide solution to produce the A549-HHP cell line. Hydrogen peroxide stock solutions were prepared in sterilized water. They were subsequently sterilized using a $0.5-\mu \mathrm{m}$ filter unit. 
In order to begin the adaptation process, cells were seeded in a $25-\mathrm{cm}^{3}$ cell culture flask. After cells reached $\sim 80 \%$ confluency, the old media was removed, and fresh media supplemented with $0.033 \mathrm{mM}$ of hydrogen peroxide solution was added to the flask. The flask was placed in the incubator and grown at $37^{\circ} \mathrm{C}$ and $5 \%$ $\mathrm{CO}_{2}$. After $24 \mathrm{~h}$, supplemented media was removed and fresh media without hydrogen peroxide solution was added to the flask. After cells reached $100 \%$ confluency, the cells were again treated with trypsin-EDTA and transferred to a flask containing fresh media without hydrogen peroxide. This process was repeated, with the concentration of hydrogen peroxide being increased with each subsequent passage, until the concentration of hydrogen peroxide reached a level of $2.4 \mathrm{mM}$. The amount by which the concentration increased with each passage ranged from $0.033-0.153 \mathrm{mM}$, with the end-point (2.4 $\mathrm{mM}$ ) was reached. This end-point was chosen because this dose was found to kill $100 \%$ of the parent cells and the A549-HNO cells (see "Verification of adaptation end-point" above). By definition, cells capable of growing in a lethal dose of hydrogen peroxide are indicative of biological changes having taken place in the A549-HHP cells when compared to the A549-parent cell line. During the adaptation process, aliquots of the adapted cells were periodically cryopreserved.

The parent cell (A549) was grown in parallel using standard conditions. Fresh media was replenished every 23 days.

\section{Photomicroscopy of tissue culture cells}

Cells were seeded in $25-\mathrm{cm}^{3}$ flasks and grown to $80 \%$ confluency with (A549-HHP) or without (A549-parent) hydrogen peroxide. Cells were imaged using a Reichert Microstart IV microscope (Reichert, Inc., Depew, NY, USA) at $\times 200$. Images were captured with Infinity $X$ $32 \mathrm{C}$ multimedia software (Immunera Corp., Ottawa, ON, Canada).

Hydrogen peroxide and DETA-NONOate challenge assays

Figure 1 represents a diagram of how the A549-HHP and A549-HNO adapted cell lines were challenged to an oxygen- or nitrogen-based free radical.

A549-parent (media without $\mathrm{NO}^{\bullet}$ donor or hydrogen peroxide), A549-HNO adapted (media with DETANONOate but without hydrogen peroxide), and A549HHP adapted cells (media without $\mathrm{NO}^{\bullet}$ donor or hydrogen peroxide) were seeded $(100 \mu \mathrm{L})$ into 96 -well plates and incubated overnight. The original media was removed and replaced by fresh media (no DETA-NONOate or hydrogen peroxide). Serial dilutions as described above were then
A549-HNO

Adapted to $\mathrm{NO}^{\circ}$

(Deta-NONOate)

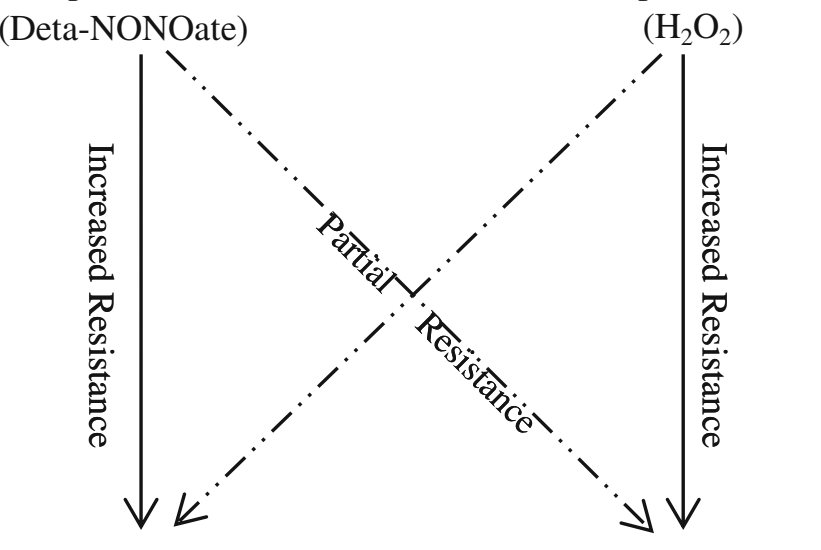

Resistance to NO

Adapted to $\mathrm{HO}^{\circ}$
A549-HHP

Fig. 1 Representation of the cross-tolerance between the A549-HNO and A549-HHP cells

carried out using $0.1 \mathrm{~mL}$ of $2400 \mathrm{uM}$ DETA-NONOate solution. The cells were then incubated at $37^{\circ} \mathrm{C}$ for an additional $72 \mathrm{~h}$, after which time MTT assays were used to measure cell viability of the parent, HNO adapted, and HHP adapted cell lines as described above. (The A549HNO cells were not maintained in DETA-NONOate media, nor were the A549-HHP cells maintained in hydrogen peroxide.) The same procedure was repeated, but with the donors being reversed for each cell line. The assays were repeated three times to validate the tolerated concentrations for parent and adapted cell lines. Individual trials were normalized, averaged, and the standard deviation was determined.

\section{Growth assays}

The MTT assay was used to measure cell proliferation/ viability of the parent and HHP adapted cells. A549-parent and A549-HHP adapted cells were seeded into 96-well microtiter plates. The cells were counted $(2,000$ cells/well) for each of the cell lines and an identical amount of cells was added to each well at the zero time point. The parent cell line was seeded and grown in the presence of RPMI1640 media formulation, and HHP adapted cells were seeded and grown in RPMI-1640 media only, or media containing $2.4 \mathrm{mM}$ hydrogen peroxide solution. MTT assays were carried out at the desired time points $(24,48$, or $72 \mathrm{~h}$ after seeding in the plates).

Doxorubicin challenge assay

A549-parent cell line and A549-HHP adapted cells were seeded into 96-well plates as described in the "Hydrogen peroxide and DETA-NONOate challenge assays" section 
above. Following overnight incubation and replenishment of media, serial dilutions were carried out using $0.1 \mathrm{~mL}$ of $6.24 \mu \mathrm{M}$ doxorubicin solution (dissolved in DMSO). MTT assays were carried out $48 \mathrm{~h}$ after exposure to doxorubicin.

Gene chip assay

A comparative analysis of A549-parent cells and A549HHP adapted cells was conducted using a "QuantArray 3.0" (PerkinElmer, Boston, MA, USA) system. Data was collected and analyzed using a R 2.9 Windows-compatible platform and the statistical analytic package "Limma 2.16" [33]. Background correction was conducted consistent with other efforts [34] using "Normexp" background correction methodology, with an "Offset" threshold value of 50 . Background correction was performed with weights of control spots positioned at 0 . Normalization was achieved by using "loess" and "scale" methods of "Normalize Within Arrays" and "Normalize Between Arrays" for within-array and between-array methodologies, respectively. Details of processes used may be found in [35]. "QuantArray" was used to control quality levels, with only those spots found acceptable by the software being included for signal transformations. Finally, normalized signals were used to determine the importance of differentiated expression levels with the use of linear modeling systems through "ImFit" and Bayes statistics achieved with the use of "eBayes" and "topTable," as previously utilized [36].

\section{Quantitative PCR analysis of mtDNA content}

To generate the standard curves to quantitate the absolute amount of mtDNA in the tumor cell lines, one region of $\mathrm{NADH}$ dehydrogenase subunit 1 (ND1) gene and one region of $\beta$-actin (ACTB) gene were cloned using the pGEM $^{\circledR}$-T Easy Vector Systems (Promega, WI, USA) according to the manufacturer's recommendation.

Table 1 lists the primers used to amplify the NADH dehydrogenase, subunit 1 (ND1) gene and $\beta$-actin (ACTB) gene using a 7500 Real Time PCR system (Applied Biosystems, Foster City, CA, USA). A $15-\mu \mathrm{L}$ reaction mixture containing $1-5 \mathrm{ng}$ of DNA template, $7.5 \mu \mathrm{L}$ of SYBR Green PCR Master Mix (Applied Biosystems), and 25 pmol of each primer was amplified for 40 cycles. Each cycle consisted of a 10 -min initial denaturation at $95^{\circ} \mathrm{C}$, followed by 15 -s denaturation at $95^{\circ} \mathrm{C}$ and 1 -min annealing/ extension at $60^{\circ} \mathrm{C}$. For each $\mathrm{qPCR}$ experiment, separate standard curves were generated from 10 serially diluted plasmids stocks (pGEM ${ }^{\circledR}$-T Easy Vector Systems; Promega) containing either mtDNA ND1 or $\beta$-actin gene fragment. To calculate the absolute mtDNA copy number of the ND1 region in each sample, the amount of ND1 was normalized against the $\beta$-actin gene. Three independent experiments were run in triplicate, and a non-template control was also included in each experiment.

Data analysis and statistics

For each MTT experiment reported herein, at least three independent experiments were conducted and a representative example is shown in the "Results" section. A minimum of four wells were run in each experiment. All values that were more than two standard deviations from the mean were not included in the final analysis of the independent experiment values, and were normalized with respect to each other and then averaged. The error bars reported represent one standard deviation from the averaged normalized mean of the reported trial.

For the quantitative PCR experiments, three independent experiments were conducted, and the reported results show the average for the three experiments \pm one standard deviation. Two-tailed Student $t$ test assuming equal variance were conducted; $P<0.05$ was considered statistically significant.

Data were graphed using SigmaPlot version 11.0 (Systat Software, Inc., Chicago, IL, USA).

\section{Results}

Verification of adaptation end-point

Prior to the adaptation of the A549-parent cells, a concentration curve was used to determine the lethal dose of hydrogen peroxide to these cells. This dose was arbitrarily chosen to be the adaptation end-point (see "Cell adaptation" section below). This process replicates our earlier work on HNO cell adaptation of A549-parent cells [32]. The HNO cells were found to have significantly altered cell biology without changing morphology, and
Table 1 Primers used to amplify the NADH dehydrogenase subunit 1 (ND1) and $\beta$-actin genes

\begin{tabular}{lll}
\hline Gene & Primer & Sequences \\
\hline NADH dehydrogenase subunit 1 (ND1) & NDF & TCAAACTACGCCCTGATCGG \\
& NDR & GGAGAGGTTAAAGGAGCCACT \\
$\beta$-Actin (ACTB) & ACTBF & TTCCTTCCTGGGCATGGAGTC \\
& ACTBR & AGACAGCACTGTGTTGGCGTA \\
\hline
\end{tabular}


therefore we hypothesized that this would also be the case for hydrogen peroxide. In the current study, $2.4 \mathrm{mM}$ hydrogen peroxide was found to consistently kill all of the parent cells after 24-h exposure as well as the A549-HNO cells (Fig. 2). Thus, $2.4 \mathrm{mM}$ was selected as the target level to maintain the cells once they were adapted.

A549-HHP cells were grown in media in which the hydrogen peroxide donor was removed and they proliferated like the parent cell line (data not shown).

The A549-parent cells were exposed in media containing $2.4 \mathrm{mM}$ hydrogen peroxide without adaptation. As expected, the parent cells were not able to survive when placed directly into media containing $2.4 \mathrm{mM}$ hydrogen peroxide (data not shown).

Cell adaptation

A549 (parent cell line) was subjected to adaptation with hydrogen peroxide to produce A549-HHP (Fig. 3). The tumor cells were passaged using trypsin-EDTA and added to a new flask which contained RPMI-1640 media only (i.e., no hydrogen peroxide was added at this time). After cells reached $\sim 80 \%$ confluency, the original media was removed and fresh media supplemented with $33 \mu \mathrm{M}$ of hydrogen peroxide was added. In the hydrogen-peroxide-containing media, cell growth was slowed, but the cells ultimately recovered. Every 2-3 days, new media containing hydrogen peroxide was added to the flask. Upon reaching confluency, the cells were passaged and divided into two flasks: the original flask, maintained at the current concentration of hydrogen peroxide solution, and a second flask in which the concentration of hydrogen peroxide was increased by approximately $0.033 \mathrm{mM}$. (As shown in Fig. 3, other concentration increments were sometimes employed, based on how fast the cells recovered from the previous increase of hydrogen peroxide.)

Each data point on the adaptation curve represents an increase in the concentration of fresh hydrogen peroxide added to the cells. As mentioned above, when cells were exposed to the next higher concentration of hydrogen peroxide, slower growth was observed, and typically, cell death-up to $\sim 60 \%$ - was observed $24 \mathrm{~h}$ later. Cells were able to recover soon after, and over a period of 3-5 days grew to confluency. When a significant amount of cell death (roughly $70 \%$ or higher) was observed, new media was replaced without hydrogen peroxide until the cells had recovered.

As shown in Fig. 3, the A549-parent cell line was successfully adapted to the target end-point concentration. The cells have been subsequently maintained at this concentration for over 12 months. The half-life of hydrogen peroxide has been reported to be anywhere from several hours to several days in water [37]; therefore, the periodic addition of hydrogen peroxide every 2-3 days resulted in a repetitive cycle of elevated transient hydrogen peroxide exposure.

Photomicroscopy of tissue culture cells

The A549-parent and the A549-HHP adapted cell lines showed no morphological differences, as seen in Fig. 4.

\section{Growth curve}

Figure 5 shows the respective growth curves for both the A549-parent and A549-HHP cells. While the A549-parent showed a robust growth rate over the $72 \mathrm{~h}$ measured, the A549-HHP in the presence of $\mathrm{H}_{2} \mathrm{O}_{2}$ had an even greater growth rate over the same time period. When the A549-HHP
Fig. 2 MTT results of the survival curve used to verify the end-point determination for A549-parent, A549-HNO, and A549-HHP

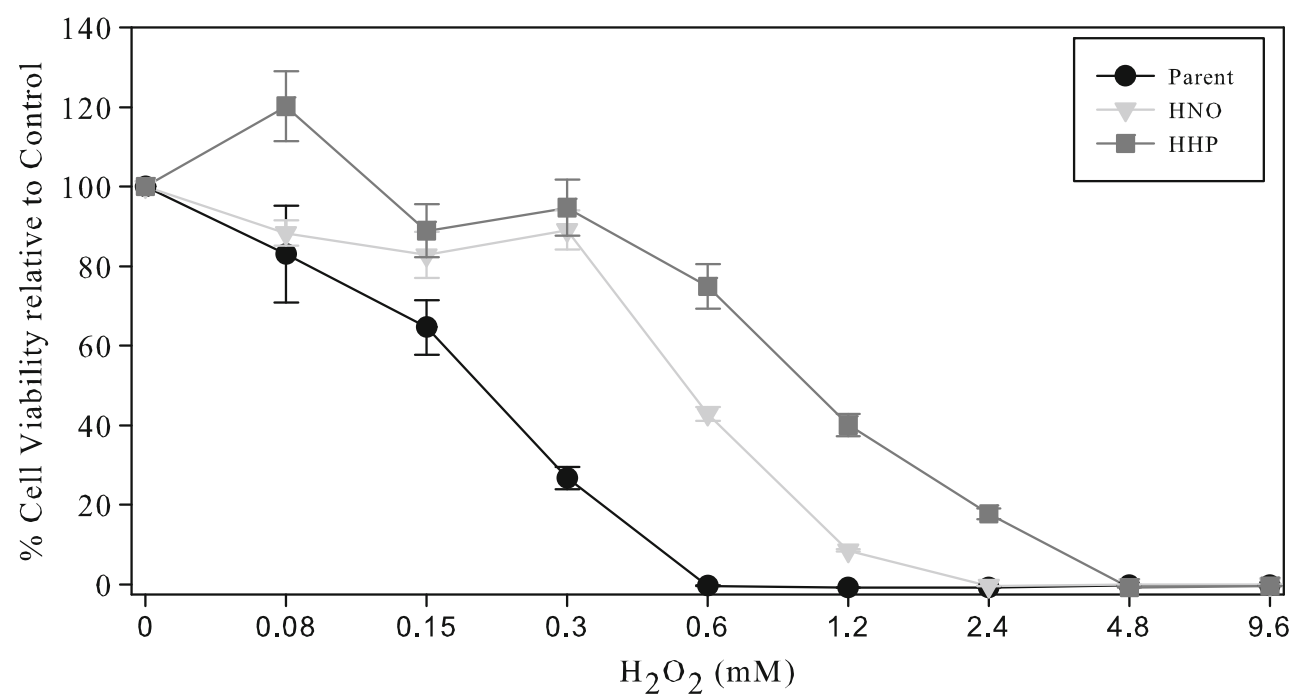


Fig. 3 Adaptation curve for the A549-parent using hydrogen peroxide which resulted in the adapted cell line A549-HHP

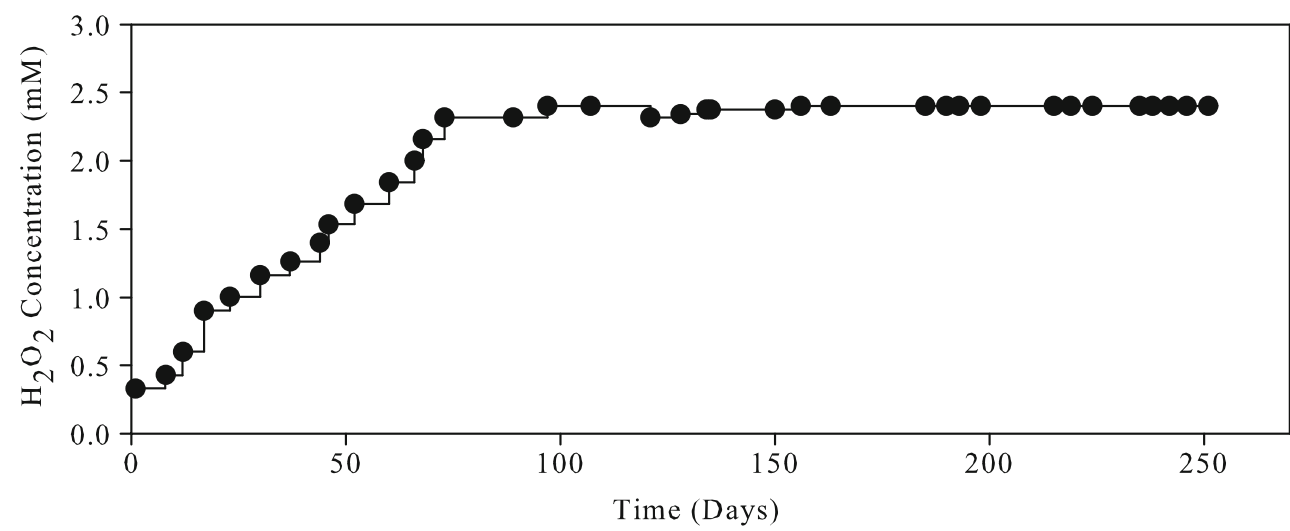

cells were grown in media lacking $\mathrm{H}_{2} \mathrm{O}_{2}$, their growth rate was almost double that of the A549-parent cells.

Hydrogen peroxide and DETA-NONOate challenge assays

In order to determine if the A549-HHP and A549-HNO adapted cells were able to survive a high free radical environment generated by nitrogen-based and oxygenbased donors, A549-parent, A549-HHP, and A549-HNO adapted cells were exposed to varying levels of hydrogen peroxide or DETA-NONOate (Figs. 2 and 6). Dosedependent growth curves are shown in Fig. $2\left(\mathrm{H}_{2} \mathrm{O}_{2}\right.$, oxygen-based donor) and Fig. 6 (DETA-NONOate, nitrogen-based donor). All three cell lines-A549-parent, A549-HHP, and A549-HNO — were killed at concentrations of $1200 \mu \mathrm{M}$ DETA-NONOate. However, at concentrations of $600 \mu \mathrm{M}$ and below, the A549-HNO cells exhibited greater viability than A549-HHP and A549-parental cells (Fig. 6). In addition, at concentrations of $2.4 \mathrm{mM}$ of $\mathrm{H}_{2} \mathrm{O}_{2}$ and below, the A549-HHP cells exhibited greater viability than A549-parent cells. When the cells were exposed to the hydrogen peroxide (Fig. 2), all three cell lines were killed at concentrations of $4.8 \mathrm{mM}$ and above. At concentrations of $2.4 \mathrm{mM}$ and below, the A549-HHP cells exhibited greater viability than A549-HNO and A549-parent cells. At concentrations of $2.4 \mathrm{mM}$ and below, the A549-HNO cells exhibited greater viability than A549-parent cells. (NoteThe A549-HHP hydrogen peroxide challenge data was added to Fig. 2 after the cell line had been adapted.)

Doxorubicin challenge assay

The A549-parent and A549-HHP cells were challenged to various concentrations of doxorubicin (Fig. 7). Doxorubicin (also known as adriamycin) is a well-known and commonly used anthracycline known to produce free radicals [38]. Because the A549-HHP cell line, which was adapted to $\mathrm{H}_{2} \mathrm{O}_{2}$, was partially cross-resistant to DETA-NONate, it was hypothesized that it would also be partially crossresistant to chemotherapeutic agents that produce free radicals. As noted in Fig. 7, the A549-HHP cell line showed a greater resistance to doxorubicin exposure than did the A549-parent cell line.

\section{Gene chip assay}

The comparison of the A549-parent to the A549-HHP cell line resulted in a total of 1,731 genes having a significant (more than a 50\%) change in gene fold expression. Among these, 811 of the genes were up-regulated, and 920 were
Fig. 4 Photomicrographs comparing the A549-parent to the A549-HHP adapted cell line $(\times 200)$

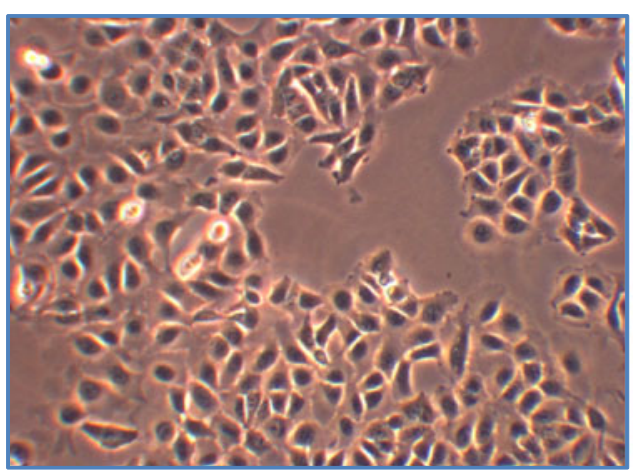

A549-Parent

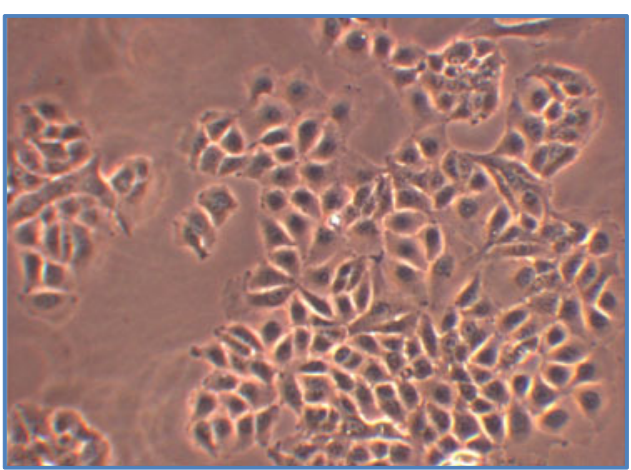

A549-HHP 


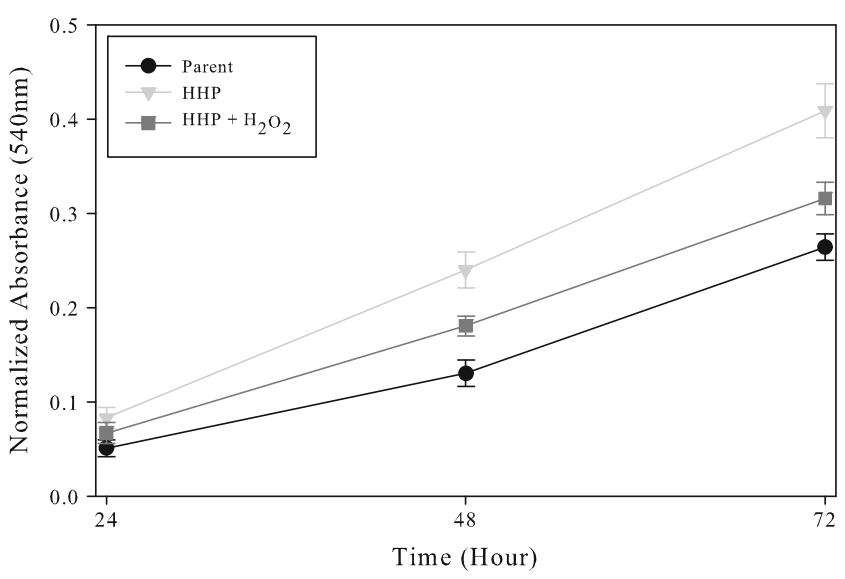

Fig. 5 Results of the MTT growth curves for the A549-parent, A549HNO, and A549-HHP at 24, 48, and $72 \mathrm{~h}$

down-regulated. Table 2 provides a list of genes with the ten highest and ten lowest gene fold change values.

Quantitative PCR analysis of mtDNA content

Using quantitative PCR to measure the copy number of mtDNA, we found that the A549-HHP cells had about a 9fold decrease in mtDNA, as shown in Fig. 8.

\section{Discussion}

In previous work from our laboratory, we were able to adapt the A549 cell line to comparatively high levels of $\mathrm{NO}^{\bullet}$ (A549-HNO). This level represented a lethal dose of the free radical $\mathrm{NO}^{\bullet}$ to the parent cell line. We have subsequently shown that the A549-HNO cell line has a comparatively more aggressive phenotype, without a corresponding change of morphology [32]. Herein we questioned whether this adapted phenotypic change was specific to the $\mathrm{NO}^{\bullet}$ free radical, or if it could be induced by any free radical. To test the hypothesis that any free radical can induce this phenotypic change, we undertook a series of studies using an oxygen-based free radical donor $\left(\mathrm{H}_{2} \mathrm{O}_{2}\right)$, rather than a nitrogen-based free radical.

Analogous to the previously reported study in which we adapted the A549 cell line to DETA-NONOate (NO donor) [32], we attempted to adapt the A549 cell line to $\mathrm{H}_{2} \mathrm{O}_{2}$. In our previous study, it was determined that $2.4 \mathrm{mM}$ was a lethal concentration of $\mathrm{H}_{2} \mathrm{O}_{2}$ to the A549-parent and A549-HNO cell lines; this result was repeated in this study for completeness. Therefore, we set out to adapt the A549parent cell line to $2.4 \mathrm{mM} \mathrm{H}_{2} \mathrm{O}_{2}$. Over the course of about 70 days, we were able to incrementally increase the dose of $\mathrm{H}_{2} \mathrm{O}_{2}$ in the A549 $\mathrm{H}_{2} \mathrm{O}_{2}$ adapted culture (A549-HHP), successfully reaching the desired end-point (Fig. 3).

As in our previously reported work, we noted the lack of a morphological change between parent cells (A549-parent) and cells adapted to lethal doses of the nitrogen-based donor DETA-NONOate (A549-HNO). After the adaptation to the lethal dose of $\mathrm{H}_{2} \mathrm{O}_{2}$, representative photomicrographs of both the A549-parent and A549-HHP cell line were prepared (Fig. 4), and again, as in this study, no noted morphological changes were observed between the parent (A549-parent) and cells adapted to the oxygen-based donor $\mathrm{H}_{2} \mathrm{O}_{2}$ (A549-HHP). This is consistent with the clinical observation of two patients presenting with morphologically identical pathology but having significantly different clinical responses. The lack of morphologic changes in part validates these adapted cell lines as a model system to study the biological differences between these two biochemically different cell types.
Fig. 6 MTT results of the challenge assay of the A549-parent, A549-HNO, and A549-HHP to the $\mathrm{NO}^{\bullet}$ donor DETANONOate

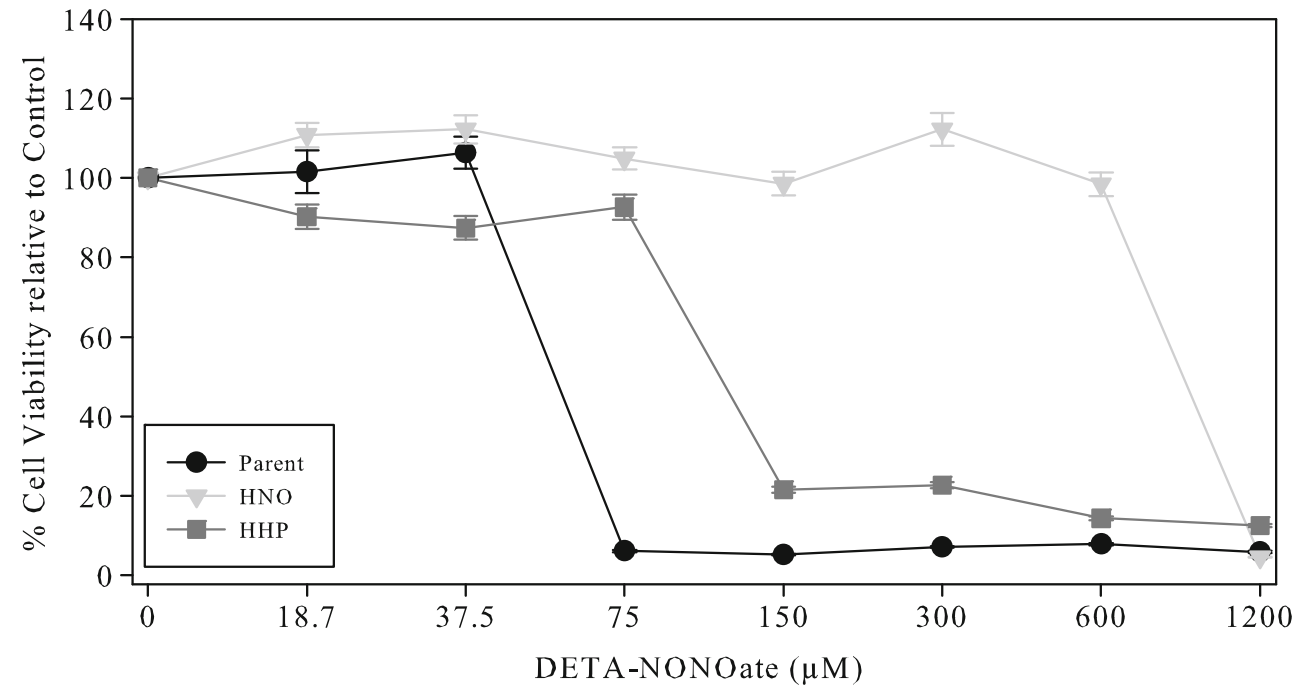


Fig. 7 MTT assay results for A549-parent and A549-HHP when challenged to varying concentrations of doxorubicin

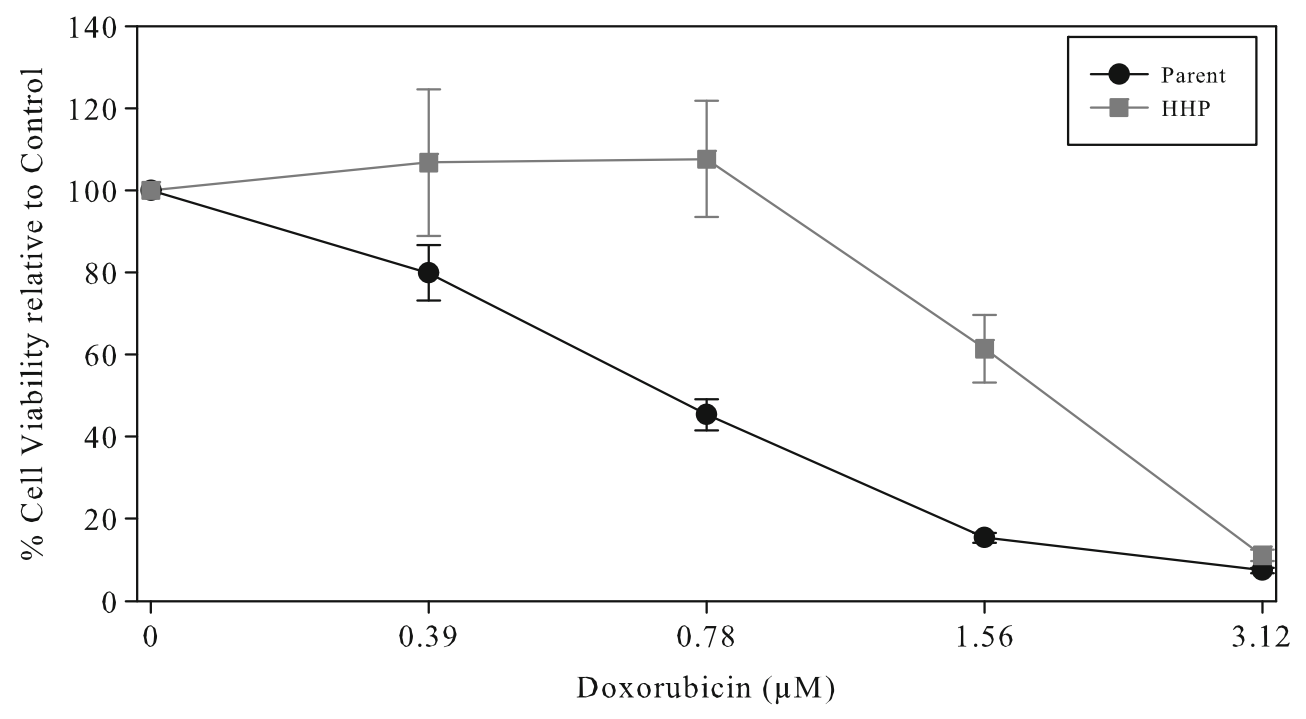

We next set out to determine if the A549-HHP cell line, which was adapted to the oxygen-based free radical, would be more or less resistant to hydrogen peroxide than the A549-HNO (nitrogen-based free radical) adapted cell line. In previous work, we have shown that the A549-HNO cell line was not only more resistant DETA-NONOate but was also more resistant to hydrogen peroxide than the parent cell line. In Fig. 2, we demonstrate that the A549-HHP cell line is more resistant to hydrogen peroxide than the A549HNO cell line, and that both of these cell lines are more resistant to hydrogen peroxide than the parent cell line. The data in this study is similar to what we previously reported for the A549-HNO cell line in that the cells that were adapted to the respective free radicals were resistant to that specific free radical but were also significantly resistant to other free radicals [32].

Table 2 Gene chip results comparing the A549-parent cell line relative to the A549-HHP adapted cell line

\begin{tabular}{|c|c|c|c|}
\hline Cell line type & Fold change & Gene symbol & Gene description \\
\hline \multirow[t]{10}{*}{ Highest: A549-parent/A549-HHP } & +14.33 & AURKC & Serine/threonine-protein kinase 13 \\
\hline & +8.76 & MMP7 & Matrilysin precursor \\
\hline & +5.48 & FXYD2 & Sodium/potassium-transporting ATPase gamma chain \\
\hline & +5.02 & LEFTY1 & Left-right determination factor 1 precursor \\
\hline & +4.54 & UGT2A3 & UDP-glucuronosyltransferase $2 \mathrm{~A} 3$ precursor \\
\hline & +4.14 & EGR1 & Early growth response protein 1 \\
\hline & +4.04 & P2RY12 & P2Y purinoceptor 12 \\
\hline & +4.03 & JUN & Transcription factor AP-1 \\
\hline & +3.96 & TP53INP1 & Tumor protein p53-inducible nuclear protein 1 \\
\hline & +3.8 & CDH17 & Cadherin-17 precursor \\
\hline \multirow[t]{10}{*}{ Lowest: A549-parent/A549-HHP } & -3.65 & KIAA1772 & GREB1-like protein \\
\hline & -3.69 & RAB20 & Ras-related protein Rab-20 \\
\hline & -3.89 & NR4A2 & Nuclear receptor subfamily 4 group A member 2 \\
\hline & -4.6 & CCL20 & C-C motif chemokine 20 precursor \\
\hline & -5.75 & NR4A3 & Nuclear receptor subfamily 4 group A member 3 \\
\hline & -6.44 & IRF2BP1 & Interferon regulatory factor 2-binding protein 1 \\
\hline & -6.57 & $\mathrm{C} 21$ orf63 & Uncharacterized protein $\mathrm{C} 21$ orf63 precursor \\
\hline & -17.18 & SLFN13 & Schlafen family member 13 \\
\hline & -69.42 & KRT13 & Keratin, type I cytoskeletal 13 \\
\hline & -264.34 & C14orf4 & Enhanced at puberty protein 1 \\
\hline
\end{tabular}

The ten most up-regulated genes, based upon fold changes, appear first, and the ten most down-regulated appear below within the A549 cell line types 


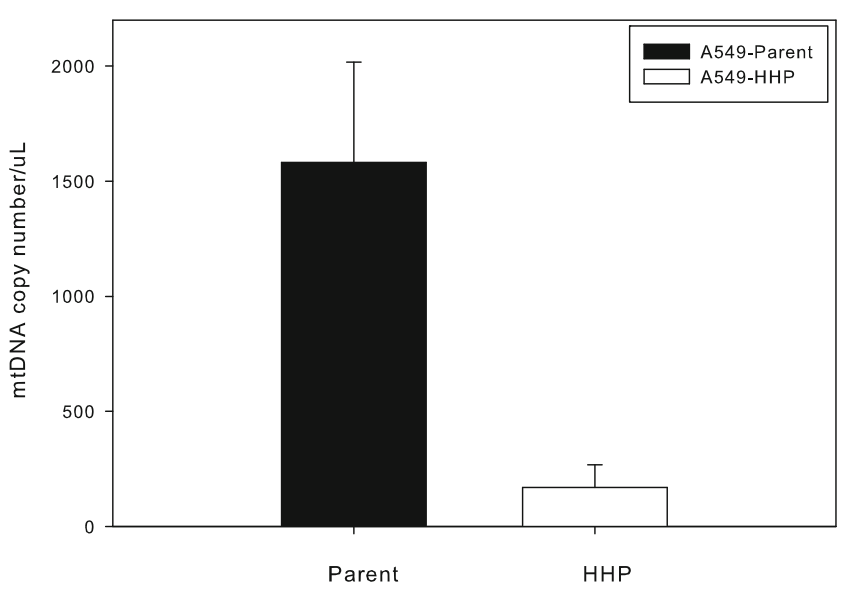

Fig. 8 Results of the qPCR analysis of mtDNA content $(p<0.05)$

The growth rates of the A549-HHP cells in media with and without $\mathrm{H}_{2} \mathrm{O}_{2}$ were greater than the A549-parent cell line (see Fig. 5). The growth properties that were noted for the $\mathrm{H}_{2} \mathrm{O}_{2}$ cells were similar to the $\mathrm{NO}^{\bullet}$ adapted A549-HNO cells as previously reported [32], in that the adapted cells grew faster than the parent cells. Combining the previous findings and the data reported herein, we have demonstrated that both nitrogen- and oxygen-based free radicals can result in phenotypic changes with increased growth rates.

We hypothesized that the A549-HHP cell line, which was adapted to $\mathrm{H}_{2} \mathrm{O}_{2}$, would exhibit more resistance to DETA-NONOate than the parent A549 cell line, but not as much as the A549-HNO (see Fig. 1). Figures 2 and 6 show the results which demonstrate this cross-resistant relationship. This finding supports the concept that a given free radical, regardless of being an oxygen- or nitrogen-based free radical, can induce resistance to other free radicals. This is important clinically because both radiation and many chemotherapeutic agents have mechanisms in which a free radical is the active form of the treatment.

In order to test this concept of cross-resistance, we measured the ability of the A549-parent and A549-HHP cells to survive in various concentrations of doxorubicin (Fig. 7). Even though these cells had not previously been exposed to doxorubicin, the A549-HHP cell line showed an enhanced ability to survive when treated with this chemotherapeutic agent. These findings imply that these adapted cells would be more resistant to any free-radical-based treatment, reflecting what is commonly found in the clinical setting.

In an effort to elucidate possible molecular mechanisms involved in the cross-resistance of the adapted cells, we compared the genome-wide expression of A549-parent and A549-HHP cell lines. As noted in Table 2, which lists the ten most up-regulated and ten most down-regulated genes based on fold changes in gene expression found in the gene chip assay studies, there is a wide range of gene products involved in multiple pathways and various cellular components that are affected by the adaptation process. The diversity of gene types observed underscores the complexity of the gene milieu that is altered upon exposure to free radicals. This reflects the known biology of human tumors in that virtually every cellular system that has been studied to date has been found to have some level of abnormality when compared to normal cells. It also points to the fact that no one gene is responsible for all of the various alterations reported herein for the A549-HHP cell line when compared to the A549-parent cell line.

Mitochondria are a source of free radical production, and more so in an aerobic than anaerobic state. The "Warburg effect" is the observation that tumor cells predominately produce energy using glycolysis (anaerobic). Because of the importance of the "Warburg effect" in tumor biology, we question if the adaptation of the A549-parent cell line to $\mathrm{H}_{2} \mathrm{O}_{2}$ would change the metabolic status of the adapted cells. We opined that such an adaptation would result in mitochondrial DNA being reduced and that the cells would move to a more anaerobic metabolic state. As noted in Fig. 8, there was a statistically significant reduction (about 9-fold; $P<0.05$ ) in the copy number of mtDNA in the A549-HHP cell line when compared to the parent cell line. As a result of this reduction, it is implied that the cells have been adapted to a more anaerobic metabolic state. As a tumor grows in size, the cells are more likely to be in a hypoxic environment and therefore would have a growth advantage if they produced their energy primarily though glycolysis.

As noted above, it is an important finding that the adapted A549-HHP cell line had identical morphology to the A549-parent cell line. The significant cellular responses to the various conditions used herein on the A549-HHP cell line underscores what is seen in the clinic. Patients frequently present having morphologically identical tumors that behave and respond differently to various treatments. The model system developed herein, which uses $\mathrm{H}_{2} \mathrm{O}_{2}$ as a way to alter the phenotypic expression of tumor cells, along with the previously reported model system which used DETA-NONOate, provides a means to study human tumor cells which reflect the spectrum of tumor types that present in the clinic. Future studies using both of these model systems will be directed at elucidating the mechanism(s) of how these aggressively growing adapted cells (utilizing two known physiologically relevant free radicals, $\mathrm{NO}^{\bullet}$ and $\left.{ }^{\bullet} \mathrm{OH}\right)$ are different from their less aggressive, nonadapted tumor cells. Understanding these mechanisms will provide new insights into how to treat aggressive tumor growth in patients. 
Acknowledgments The authors wish to thank Dr. Zarema Arbieva, Ms. WeiHua Wang, and Mr. Oleksiy Karpenko at the University of Illinois at Chicago Core Genomics Facility for their assistance in conducting the gene chip experiments. The authors would also like to thank Ms. Falise Platt for her assistance in preparing this manuscript.

Conflicts of interest None

\section{References}

1. Jemal A, Tiwari RC, Murray T, Ghafoor A, Samuels A, Ward E, Feuer EJ, Thun MJ. Cancer statistics. CA Cancer J Clin. 2004;54:8-29.

2. US National Institute of Health, National Institute of Cancer Statistics, 2010.

3. Ames BN. Endogenous oxidative DNA damage, aging, and cancer. Free Radic Res Commun. 1989;7:121-8.

4. Cerutti PA. Oxy-radicals and cancer. Lancet. 1994;344:862-3.

5. Feig DI, Reid TM, Loeb LA. Reactive oxygen species in tumorigenesis. Cancer Res. 1994;54:1890s-4s.

6. Ohshima $\mathrm{H}$, Bartsch $\mathrm{H}$. Chronic infections and inflammatory processes as cancer risk factors: possible role of nitric oxide in carcinogenesis. Mutat Res. 1994;305:253-64.

7. Routledge MN, Wink DA, Keefer LK, Dipple A. DNA sequence changes induced by two nitric oxide donor drugs in the supf assay. Chem Res Toxicol. 1994;7:628-32.

8. Totter JR. Spontaneous cancer and its possible relationship to oxygen metabolism. Proc Natl Acad Sci USA. 1980;77:1763-7.

9. Halliwell B. Antioxidants in human health and disease. Annu Rev Nutr. 1996;16:33-50.

10. Chatterjee S, Fisher AB. Ros to the rescue. Am J Physiol. 2004;287:L704-705

11. Hancock JT, Desikan R, Neill SJ. Role of reactive oxygen species in cell signalling pathways. Biochem Soc Trans. 2001;29:345-50.

12. Sauer H, Wartenberg M, Hescheler J. Reactive oxygen species as intracellular messengers during cell growth and differentiation. Cell Physiol Biochem. 2001;11:173-86.

13. Taniyama Y, Griendling KK. Reactive oxygen species in the vasculature: molecular and cellular mechanisms. Hypertension. 2003;42:1075-81.

14. Burdon RH. Superoxide and hydrogen peroxide in relation to mammalian cell proliferation. Free Radic Biol Med. 1995;18:77594

15. Schreck R, Albermann K, Baeuerle PA. Nuclear factor kappa b: an oxidative stress-responsive transcription factor of eukaryotic cells (a review). Free Radic Res Commun. 1992;17:221-37.

16. Jackson JH. Potential molecular mechanisms of oxidant-induced carcinogenesis. Environ Health Perspect. 1994;102 Suppl 10:1557.

17. Sarafian TA, Bredesen DE. Is apoptosis mediated by reactive oxygen species? Free Radic Res. 1994;21:1-8.

18. Henle ES, Linn S. Formation, prevention, and repair of DNA damage by iron/hydrogen peroxide. J Biol Chem. 1997;272:19095-8.

19. Hunt CR, Sim JE, Sullivan SJ, Featherstone T, Golden W, Von Kapp-Herr C, Hock RA, Gomez RA, Parsian AJ, Spitz DR. Genomic instability and catalase gene amplification induced by chronic exposure to oxidative stress. Cancer Res. 1998;58:398692.

20. Imlay JA, Linn S. DNA damage and oxygen radical toxicity. Science (New York, NY). 1988;240:1302-9.

21. Jackson AL, Loeb LA. Microsatellite instability induced by hydrogen peroxide in Escherichia coli. Mutat Res. 2000;447:18798
22. Park S, You X, Imlay JA. Substantial DNA damage from submicromolar intracellular hydrogen peroxide detected in $\mathrm{Hpx}^{-}$ mutants of Escherichia coli. Proc Natl Acad Sci USA. 2005; 102:9317-22.

23. Pericone CD, Bae D, Shchepetov M, McCool T, Weiser JN. Short-sequence tandem and nontandem DNA repeats and endogenous hydrogen peroxide production contribute to genetic instability of Streptococcus pneumoniae. J Bacteriol. 2002;184:4392-9.

24. Polytarchou C, Hatziapostolou M, Papadimitriou E. Hydrogen peroxide stimulates proliferation and migration of human prostate cancer cells through activation of activator protein-1 and upregulation of the heparin affin regulatory peptide gene. J Biol Chem. 2005;280:40428-35.

25. Zanetti M, Katusic ZS, O'Brien T. Adenoviral-mediated overexpression of catalase inhibits endothelial cell proliferation. Am J Physiol Heart Circ Physiol. 2002;283:H2620-2626.

26. Brown MR, Miller Jr FJ, Li WG, Ellingson AN, Mozena JD, Chatterjee P, Engelhardt JF, Zwacka RM, Oberley LW, Fang X, Spector AA, Weintraub NL. Overexpression of human catalase inhibits proliferation and promotes apoptosis in vascular smooth muscle cells. Circ Res. 1999;85:524-33.

27. del Bello B, Paolicchi A, Comporti M, Pompella A, Maellaro E. Hydrogen peroxide produced during gamma-glutamyl transpeptidase activity is involved in prevention of apoptosis and maintainance of proliferation in $\mathrm{u} 937$ cells. FASEB J. 1999;13:69-79.

28. Arbiser JL, Petros J, Klafter R, Govindajaran B, McLaughlin ER, Brown LF, Cohen C, Moses M, Kilroy S, Arnold RS, Lambeth JD. Reactive oxygen generated by nox1 triggers the angiogenic switch. Proc Natl Acad Sci USA. 2002;99:715-20.

29. Qian Y, Luo J, Leonard SS, Harris GK, Millecchia L, Flynn DC, Shi X. Hydrogen peroxide formation and actin filament reorganization by $\operatorname{cdc} 42$ are essential for ethanol-induced in vitro angiogenesis. J Biol Chem. 2003;278:16189-97.

30. Nishi H, Nakada T, Kyo S, Inoue M, Shay JW, Isaka K. Hypoxiainducible factor 1 mediates upregulation of telomerase (htert). Mol Cell Biol. 2004;24:6076-83.

31. Nishikawa M, Tamada A, Hyoudou K, Umeyama Y, Takahashi Y, Kobayashi Y, Kumai H, Ishida E, Staud F, Yabe Y, Takakura Y, Yamashita F, Hashida M. Inhibition of experimental hepatic metastasis by targeted delivery of catalase in mice. Clin Exp Metastasis. 2004;21:213-21.

32. Radosevich JA, Elseth KM, Vesper BJ, Tarjan G, Haines III GK. Long-term adaptation of lung tumor cell lines with increasing concentration of nitric oxide donor. Open Lung Canc J. 2009;2:35-44.

33. Smyth GK, Gentleman R, Carey V, Dudoit S, Irizarry R, Huber W. Limma: Linear models for microarray data. Bioinformatics and Computational Biology Solutions Using $\mathrm{R}$ and Bioconductor 2005;397-420

34. Ritchie ME, Silver J, Oshlack A, Holmes M, Diyagama D, Holloway A, Smyth GK. A comparison of background correction methods for two-colour microarrays. Bioinformatics (Oxford, England). 2007;23:2700-7.

35. Smyth GK, Speed T. Normalization of cDNA microarray data. Methods (San Diego, Calif). 2003;31:265-73.

36. Smyth GK. Linear models and empirical Bayes methods for assessing differential expression in microarray experiments. Stat Appl Genet Mol Biol 2004;3:Article3.

37. Hinchee RE, Downey DC, Aggarwal PK. Use of hydrogen peroxide as an oxygen source for in situ biodegradation: Part I. Field studies. J Hazard Mat. 1991;27:287-99.

38. Campbell KJ, O'Shea JM, Perkins ND. Differential regulation of NF-kappaB activation and function by topoisomerase II inhibitors. BMC Cancer. 2006;6:101. 